\title{
Challenges and Opportunities in Gen3 Embedded Cooling with High-Quality Microgap Flow
}

\author{
Avram Bar-Cohen ${ }^{1}$, Franklin L. Robinson ${ }^{2}$, and David C. Deisenroth ${ }^{3}$ \\ ${ }^{\prime}$ Space and Airborne Systems, Raytheon Company, Arlington, VA 22209, USA \\ ${ }^{2}$ Thermal Engineering Branch, NASA Goddard Space Flight Center, Greenbelt, MD 20771, USA \\ ${ }^{3}$ Department of Mechanical Engineering, University of Maryland, College Park, MD 20742, USA
}

\begin{abstract}
Gen3, Embedded Cooling, promises to revolutionize thermal management of advanced microelectronic systems by eliminating the sequential conductive and interfacial thermal resistances which dominate the present "remote cooling" paradigm. Single-phase interchip microfluidic flow with high thermal conductivity chips and substrates has been used successfully to cool single transistors dissipating more than $40 \mathrm{~kW} / \mathrm{cm}^{2}$, but efficient heat removal from transistor arrays, larger chips, and chip stacks operating at these prodigious heat fluxes would require the use of high vapor fraction (quality), twophase cooling in intra- and inter-chip microgap channels. The motivation, as well as the challenges and opportunities associated with evaporative embedded cooling in realistic form factors, is the focus of this paper. The paper will begin with a brief review of the history of thermal packaging, reflecting the 70-year "inward migration" of cooling technology from the computer-room, to the rack, and then to the single chip and multichip module with "remote" or attached air- and liquid-cooled coldplates. Discussion of the limitations of this approach and recent results from singlephase embedded cooling will follow. This will set the stage for discussion of the development challenges associated with application of this Gen3 thermal management paradigm to commercial semiconductor hardware, including dealing with the effects of channel length, orientation, and manifold-driven centrifugal acceleration on the governing behavior.
\end{abstract}

Keywords-embedded cooling; electronics cooling; two-phase flow; heat transfer; microgap; microchannel

\section{STATE-OF-THE-ART IN EMBEDDED COOLING}

The increased integration density of electronic components and subsystems, including the nascent commercialization of 3D chip stack technology, has exacerbated the thermal management challenges facing electronic system developers. The confluence of chip power dissipation above $100 \mathrm{~W}$, localized hot spots with fluxes above $1 \mathrm{~kW} / \mathrm{cm}^{2}$, and package-level volumetric heat generation that can exceed $1 \mathrm{~kW} / \mathrm{cm}^{3}$ has exposed the limitations of the current "remote cooling" paradigm and its inability to support continued enhancements in the performance of advanced silicon and compound semiconductor components. These thermal limitations have compromised the decades-long Moore's law progression in microprocessor performance and threaten to derail the innovation engine which has been responsible for much of the microelectronic revolution [1,2].

In conventional cooling architectures for electronics, reliance on thermal conduction and spreading, in the commonlyused chips and substrates and across the multiple material interfaces present in packages and modules, severely constrains the ability of remotely located heat rejection surfaces to reduce the temperature rise of critical on-chip hot spots and individual chips in a module or in a stack. Moreover, continued application of this "remote cooling" paradigm has resulted in advanced electronic systems in which the thermal management hardware accounts for a large fraction of the volume, weight, and cost, and undermines efforts to transfer emerging electronic components to portable, as well as other small form-factor, applications. Consequently, many commercial and military electronic systems are today "thermally-limited," i.e., performing well below the inherent electrical capability of the device technology they exploit. To overcome these limitations and remove a significant barrier to continued Moore's law progression in electronic components and systems, it is essential to "embed" aggressive thermal management in the chip, substrate, and/or package and directly cool the heat generation sites. The development of such "Gen3" thermal management technology, following on the Gen 1 air-conditioning approaches of the early years and the decades-long commitment to the Gen2 "remote cooling" paradigm, has been spearheaded by the Defense Advanced Research Projects Agency (DARPA) [3-5] and embraced by many organizations [2,6-8].

The Near Junction Thermal Transport (NJTT) program, initiated in 2011, was the first program to develop thermal management for the region within $100 \mu \mathrm{m}$ of the electrical junction of a gallium nitride $(\mathrm{GaN})$ transistor and aimed to enable heat fluxes of greater than $100 \mathrm{~W} / \mathrm{mm}^{2}\left(10 \mathrm{~kW} / \mathrm{cm}^{2}\right)$ while maintaining reliable junction temperatures. Through technology developed in this program, specifically the placement of GaN epitaxy on - or in close proximity to-high thermal conductivity diamond, the RF power handling capability of GaN high-electron-mobility transistor (HEMT) devices was increased by greater than a factor of 3 [9-14], to in excess of $500 \mathrm{~W} / \mathrm{mm}^{2}$ of RF power and more than $400 \mathrm{~W} / \mathrm{mm}^{2}$ of heat, as shown in Fig. 1 and described in greater detail in $[8,15]$.

While the NJTT program made significant gains using high thermal conductivity substrates to spread the heat close to the junction, it did not address the next link in the thermal resistance chain, i.e. extracting the heat from the diamond and transferring that dissipated heat to an available coolant. In the Computational track of the DARPA ICECool Applications program, IBMwhich had earlier demonstrated an ability to remove nearly $4 \mathrm{~kW} / \mathrm{cm}^{3}$ from a chip stack with inter-chip (or interlayer) fluid flow [16] — used the evaporation of a refrigerant flowing radially across a single chip to successfully control the temperature of a $2 \mathrm{~kW} / \mathrm{cm}^{2}$ hot spot in cores dissipating greater than $350 \mathrm{~W} / \mathrm{cm}^{2}$ 
on a Power PC7 chip $[17,18]$. Georgia Tech, working with IntelAltera to apply liquid cooling to a field-programmable gate array (FPGA) chip, was able to demonstrate a significant increase $(\sim 1.5 \mathrm{x})$ in computational throughput for the Stratix 5 by using forced flow across the back of the chip to reduce leakage currents and simultaneously cooling all 9 cores on the chip [19].

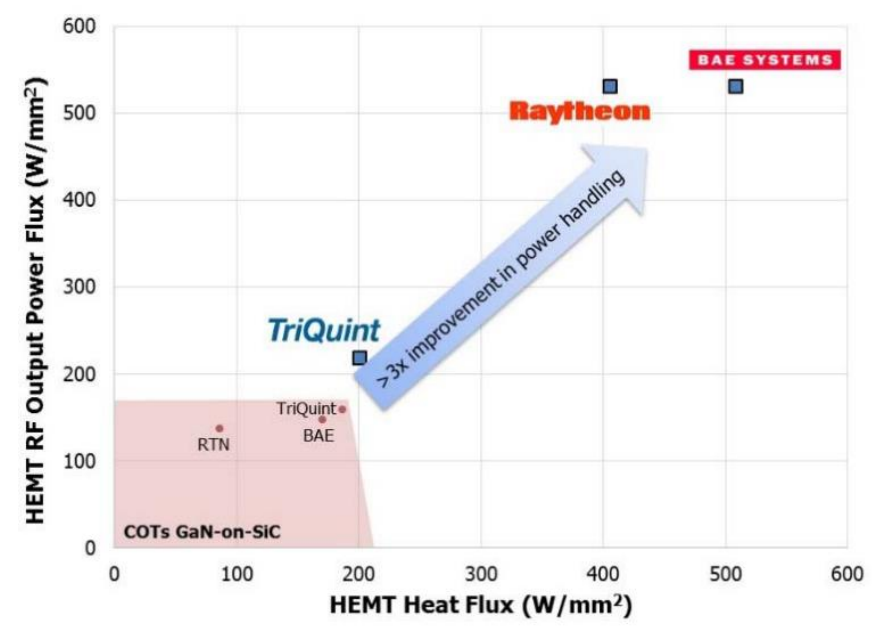

Fig. 1: Improvement achieved by NJTT performers in HEMT RF areal power density, the RF output power over the footprint of the HEMT, as a result of enhanced thermal management enabling operation at higher transistor RF heat fluxes, the heat dissipated over the footprint of the HEMT, adapted from [7]

The Power Amplifier track of the DARPA ICECool Applications program, which began in 2013 [5] and is now nearing completion, combined embedded single-phase microfluidics with high thermal conductivity substrates to reduce the thermal resistances in the entire monolithic microwave integrated circuit (MMIC) package. The successful demonstration of embedded microfluidic cooling of the MMIC substrates with bonded, liquid manifolds, by all participating research teams, is displayed in Fig. 2. It may be noted that these results offer $1 \mathrm{~kW} / \mathrm{cm}^{2}$ cooling for the entire chip (approximately $5 \mathrm{~mm}$ by $5 \mathrm{~mm}$ ) and record-level HEMT transistor heat removal rates of more than $30 \mathrm{~kW} / \mathrm{cm}^{2}$ or $300 \mathrm{~W} / \mathrm{mm}^{2}[15]$.



Fig. 2: ICECool Applications Phase 1 TDV Results [15]
The dramatic improvements in demonstrated singletransistor heat removal rates provide a most compelling validation of Embedded Cooling and set the stage for commercial and military applications of this Gen3 thermal management paradigm. However, if such efficient $\mathrm{kW}$-level heat removal is to be extended from single transistors to transistor arrays, larger chips, and chip stacks, it will be necessary to fully exploit the latent heat of evaporation of the flowing liquid through two-phase local cooling and high exit vapor fractions. To harness such high-quality, vigorous phasechange processes in embedded microchannels, cut through the chips and/or in inter-chip microgap channels, requires a fundamental understanding of the underlying hydrodynamic behavior and thermal characteristics of two-phase flow in manifold-supplied chip-scale coolers operating in a variety of orientations. Subsequent sections will identify the challenges implicit in widespread application of embedded two-phase cooling and provide recent results from the authors' work in such configurations [20-24].

\section{THERMOFLUID CHARACTERISTICS OF TWO-PHASE LABORATORY MICROGAP CHANNELS}

In two-phase flow, the extent, aggregation, and distribution of each phase is classified into distinct categories called flow regimes. The dominant regimes in two-phase microgap flow are bubbly, intermittent, and annular flow [25]. Bubbly flow is observed at the low qualities and consists of small, spherical bubbles, dispersed and transported by the continuous liquid phase. With increasing flow quality, the bubbles grow and coalesce until eventually confined by the lateral bounds of the channel and then continue to elongate axially. This distribution of large vapor slugs, separated by liquid plugs or bridges, is known as intermittent flow. As the vapor fraction continues to increase, the larger vapor bubbles coalesce into a continuous annular configuration, consisting of a high-velocity vapor core, and thin, shear-driven, liquid film around the perimeter of the channel. These flow regimes can be clearly seen in Fig. 3 for the two-phase flow of R134a in a $0.79 \mathrm{~mm}$ diameter channel.

(a)

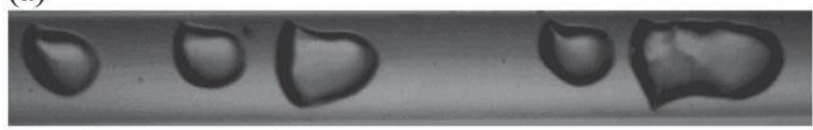

(b)

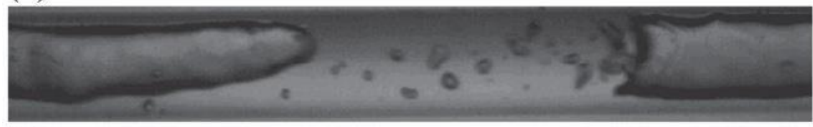

(c)

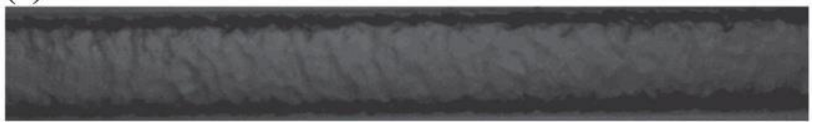

Fig. 3: Prevailing flow regimes in microscale channels for R134a flowing at $500 \mathrm{~kg} / \mathrm{m}^{2}$-s in a $0.79 \mathrm{~mm}$ diameter tube: (a) bubbly flow at $\mathrm{x}=0$, (b) intermittent flow at $x=0.11$, and (c) annular flow at $x=0.73[26]$

Recent studies [27-33] of two-phase thermofluid behavior in relatively long $(100<L / D<500)$ microgap channels have uncovered a strong dependence of the previously observed Mshape variation in heat transfer coefficient, as seen in Fig. 4, on the prevailing two-phase flow regimes. The low-quality peak in 
the M-shape heat transfer coefficient profile corresponds to the incipience of nucleate boiling or bubbly flow. The bubble nucleation, movement, and acceleration disrupt and thin the thermal boundary layer, all of which enhance the heat transfer coefficient. With the additional increase in quality, the flow quickly progresses from bubbly to intermittent flow. In intermittent flow, the thermal transport enhancement attributed to bubbly flow is gradually suppressed by the confinement of large vapor bubbles and decreasing liquid plug length, resulting in an overall deterioration in the heat transfer coefficient with increasing flow quality. However, this deterioration is soon overcome by the transition from intermittent to annular flow and driven by the increasing vapor-liquid velocity difference and thinning of the evaporating liquid film, resulting in an inflection and monotonic increase in the heat transfer coefficient, until reaching a second maximum and then followed by a deterioration that asymptotically approaches the value for single-phase vapor convection. The specific mechanisms responsible for this high-quality peak and deterioration in the heat transfer coefficient are poorly understood and have constrained the design, optimization, and implementation of two-phase coolers in the favorable high-quality domain.

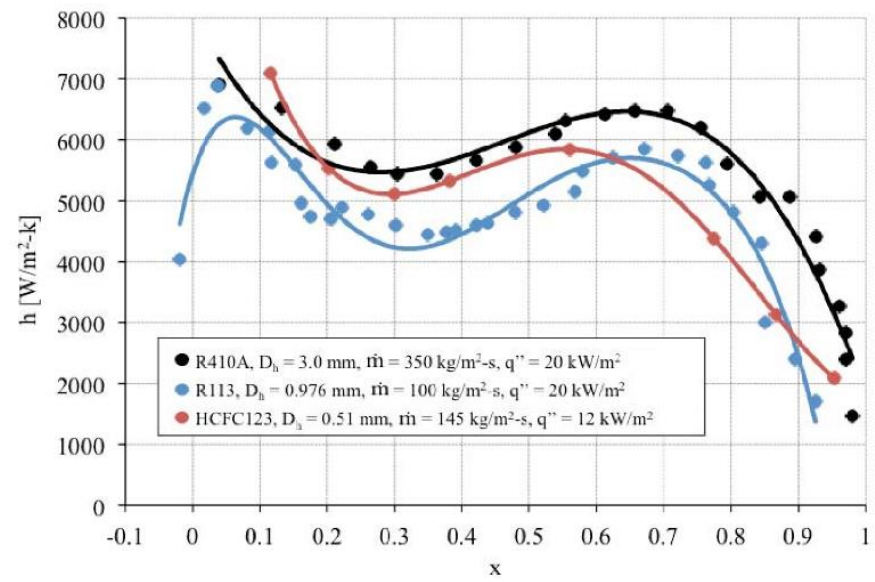

Fig. 4: Characteristic M-shape variation in the heat transfer coefficient for two-phase refrigerant flow in microgap channels. Data from [31-33].

In an investigation of the mechanisms responsible for the thermal deterioration observed in high-quality annular flow, Kabov, Zaitsev, Cheverda, and Bar-Cohen [34] empirically simulated an adiabatic shear-driven liquid film in a $40 \mathrm{~mm}$ by $80 \mathrm{~mm}$ by $2 \mathrm{~mm}$ channel by independently injecting liquid FC-72 and gaseous nitrogen streams. Deformations and emerging patterns were observed at the liquid-vapor interface and, depending on the flow rate of each phase, were classified into five sub-regimes: (1) cells, (2) structures, (3) 2D waves, (4) $3 \mathrm{D}$ waves, and (5) film rupture. The sub-regime map of the interfacial deformations and a photographic example of the 2D and 3D wave patterns are shown in Fig. 5. At low liquid and vapor velocities, the deformations in the liquid film are weak and classified as cells and structures. As the vapor velocity increases, periodic 2D waves emerge on the surface of the liquid film; the frequency of the $2 \mathrm{D}$ waves increases with vapor velocity until eventually evolving into a $3 \mathrm{D}$ wave structure. For low liquid film flow rates and sufficiently large vapor velocities, the liquid film ruptures and is torn from surface. The observed deformations and rupture of the shear-driven liquid film may be responsible for the thermal deterioration at high vapor qualities in diabatic microgap channels, as observed and reported in $[20,21,35]$.
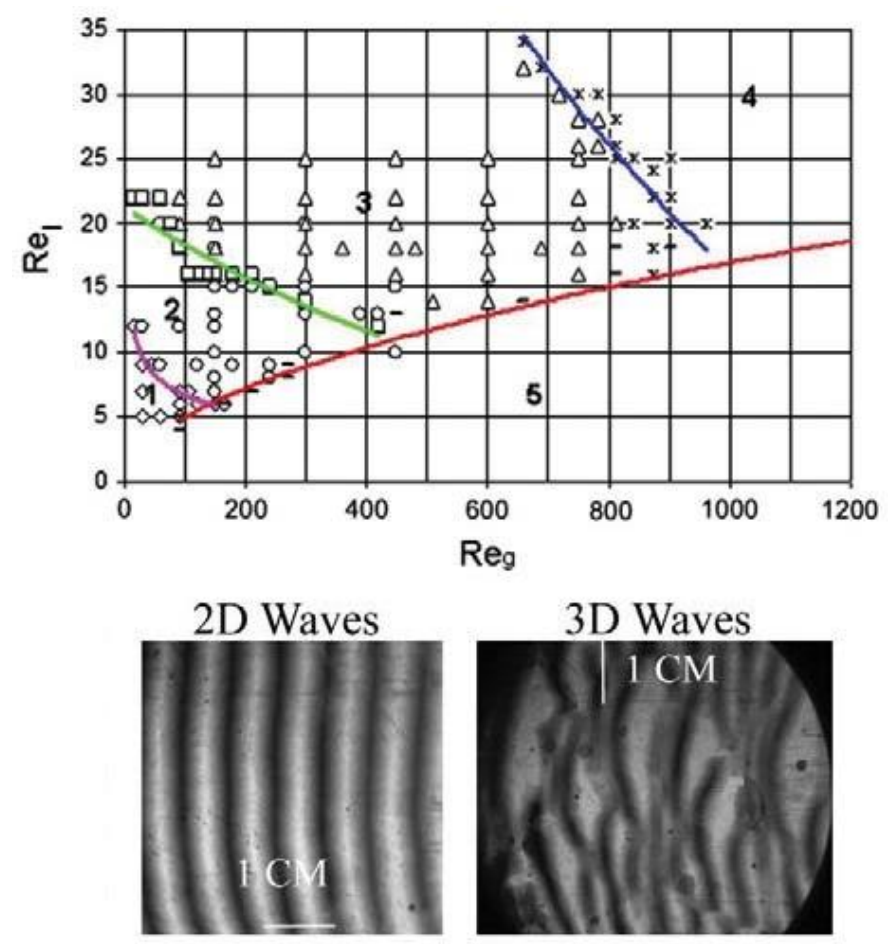

Fig. 5: Sub-regime map and visualization of interfacial deformations for two-phase flow of FC-72 and nitrogen in a mini-channel, where: (1) cells,

(2) structures, (3) 2D waves, (4) 3D waves, and (5) film rupture [34]

\section{CHIP-ScAlE EFFECTS IN MicROGAP COOLERS}

In applying microgap two-phase cooling to operational electronic equipment, attention needs to be focused on relatively short, low length-to-diameter ratio $(L / D<100)$ "chip-scale" configurations, operating at moderate to high heat fluxes and high qualities; these differ considerably from the conditions studied in much of the literature. Recently published studies $[26,29,36,37]$ have shed considerable light on the characteristics of such chip-scale microgap channels, but these initial results are insufficient to establish the axial progression in flow regimes and the resulting variation (M-shaped or otherwise) of the local heat transfer coefficient. Consequently, Bar-Cohen and Holloway [21] undertook an effort to provide an in-depth exploration of the two-phase thermofluid behavior of a chipscale microgap channel using both photographic and infrared temperature visualizations. The photographic visualization was used to identify prevailing flow regimes, while the infrared visualization targeted the associated spatial and temporal wall temperature variations and their associated heat transfer coefficients.

In the Bar-Cohen and Holloway study [21], FC-72 was pumped through a $10 \mathrm{~mm}$ by $12 \mathrm{~mm}$ by $0.2 \mathrm{~mm}$ microgap channel at a constant flow rate of $0.25 \mathrm{ml} / \mathrm{s}$ (corresponding to a mass flux of $210 \mathrm{~kg} / \mathrm{m}^{2}$-s) with an inlet subcooling of $5 \mathrm{~K}$. Heat was applied uniformly to the bottom of the microgap channel at a constant rate of $7.5,15.0,22.5$, or $30 \mathrm{~W}$, corresponding to a heat flux of $2.8,7.9,13.1$, or $17.7 \mathrm{~W} / \mathrm{cm}^{2}$, and exit quality of 
$0.09,0.27,0.45$, or 0.61 . This set of conditions was chosen in order to span a wide range of flow qualities and regimes while remaining below the temperature limit of the resistance heater used in the microgap test section $\left(100^{\circ} \mathrm{C}\right)$. The surface temperatures measured by the infrared camera were used to calculate the time-averaged heat flux distribution, which in turn was used to calculate the heat transfer coefficient distribution at the wetted microgap surface. Photographic visualization was used to evaluate the dominant flow regimes for each set of conditions and compared to the thermal data to determine any interdependence between the two.

A schematic of the experimental flow loop used in this study is shown in Fig. 6 and described in detail in [21]. A top-down, cross-sectional and exploded view of the assembled copper microgap test section is shown in Fig. 7. There are two small ridges on each side of the microgap, used to set the channel gap and support the sapphire window which confines the upper surface of the microgap channel and is transparent in both the visual and midwave infrared spectrums. Heat is applied to the bottom of the microgap pedestal with a $12 \mathrm{~mm}$ by $12 \mathrm{~mm}$ ceramic resistive heater. Five vertical holes were drilled into the underside of the microgap channel, along the centerline, ending $1 \mathrm{~mm}$ below the microgap surface, to allow placement of E-type thermocouples to measure the centerline temperature of the microgap heated wall. The microgap surface is coated with a thin layer of Aeroglaze Z307 Polyurethane Coating to provide a high and uniform emissivity for infrared temperature measurements. The paint is $38 \mu \mathrm{m}(0.0015$ ") thick and has a thermal conductivity of $0.35 \mathrm{~W} / \mathrm{m}-\mathrm{K}$.

The synchronized photographic and infrared visualization for a mass flux of $210 \mathrm{~kg} / \mathrm{m}^{2}$-s is shown in Fig. 8 through Fig. 11 for an exit quality of $9 \%, 27 \%, 45 \%$, and $61 \%$, respectively. For each case, two sets of visualization-captured at different times, with the first (left) image reflecting "typical" conditions and the second (right) image reflecting occasional or atypical behavior - are presented to demonstrate the unsteady nature of the flow. The flow is from left to right for all images presented.

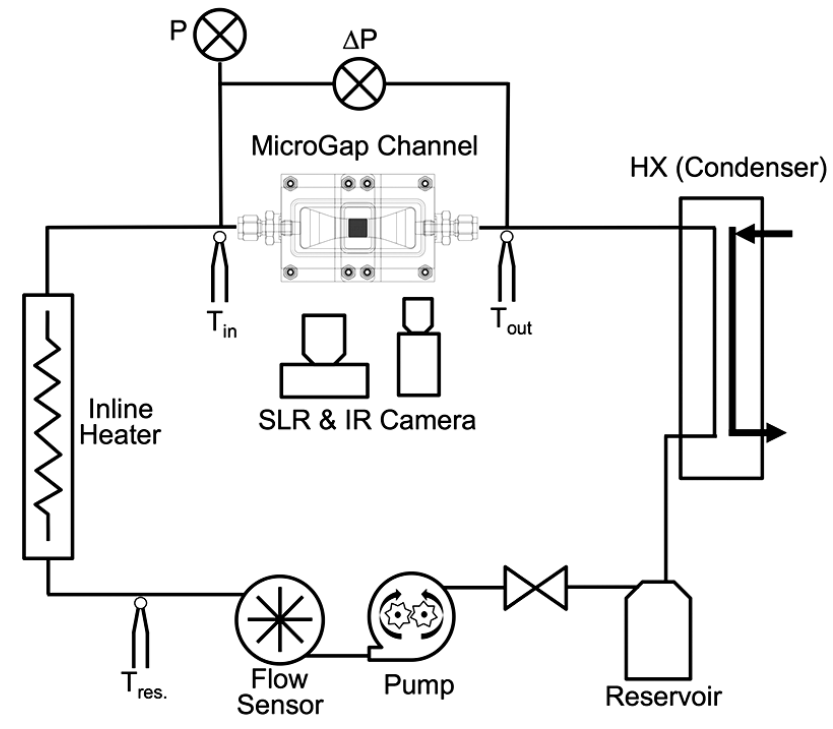

Fig. 6: Schematic of flow loop apparatus [21]
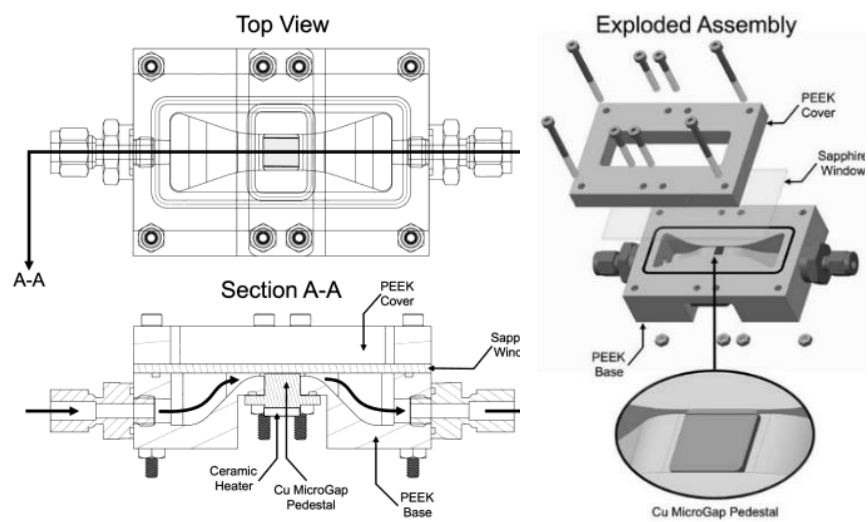

Fig. 7: Test section assembly for microgap channel, top, cross sectional view (left) and exploded view (right) [21]

At a heat flux of $2.8 \mathrm{~W} / \mathrm{cm}^{2}$ and an exit quality of $9 \%$, bubbly flow is the dominant flow regime, as shown in Fig. 8(a). However, as shown in Fig. 8(b), large, confined vapor bubbles are occasionally observed to consume most of the channel and, in doing so, induce a brief 2 to $3 \mathrm{~K}$ increase in wall temperature.



(a)

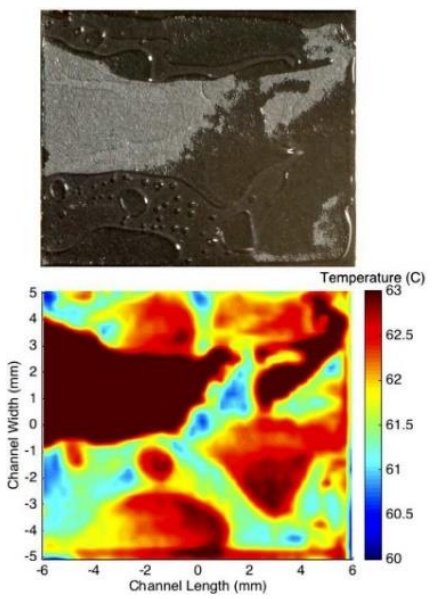

(b)
Fig. 8: Instantaneous photographic and infrared visualization of twophase diabatic microgap flow for FC-72, $q "=2.8 \mathrm{~W} / \mathrm{cm}^{2}, \mathrm{x}_{\text {exit }}=9 \%, \mathrm{~h}_{\text {avg }}$ $=4300 \mathrm{~W} / \mathrm{m}^{2}-\mathrm{K}, \mathrm{G}=210 \mathrm{~kg} / \mathrm{m}^{2}-\mathrm{s}, \Delta \mathrm{T}_{\text {sub }}=5 \mathrm{~K}$, and a $10 \mathrm{~mm}$ by $12 \mathrm{~mm}$ by $0.2 \mathrm{~mm}$ channel (a) Typical and (b) Occasional. Flow is left to right.

As the heat flux increases to $7.9 \mathrm{~W} / \mathrm{cm}^{2}$ and the exit quality to $27 \%$, bubbly flow persists at the entrance of the channel but the vapor bubbles grow and coalesce at a considerably faster rate, as shown in Fig. 9(a). At this point, the flow for the second half of the channel consists of very large, confined vapor bubbles that occasionally (Fig. 9(b)) grow to fill much of the channel, and may be classified as "churning" intermittent flow. This "churning" flow of confined bubbles appears to initiate periodic dryout of the liquid film on the heated wall, producing more significant, 8 to $10 \mathrm{~K}$, wall temperature fluctuations.

As the heat flux continues to $15.7 \mathrm{~W} / \mathrm{cm}^{2}$ and the exit quality to $45 \%$, periodic intermittent flow dominates most of the microgap channel and bubbly flow is limited, on average, to only the first few millimeters of the channel length, as shown in Fig. 10(a). In the lower left-hand corner of the photographic image shown in Fig. 10(a), local dryout is observed to occur along the bottom of the vapor bubbles and periodically grows to consume a large portion of the channel, oscillating vigorously 
between the conditions shown in Fig. 10(a) and Fig. 10(b), respectively. Under the influence of the higher wall heat flux, the average wall "excess" temperature increases to approximately $25 \mathrm{~K}$ above the inlet liquid temperature of $51{ }^{\circ} \mathrm{C}$, but more vigorous churning flow limits the local wall temperature fluctuations to 8 to $10 \mathrm{~K}$, the same range as the previous heat flux condition.

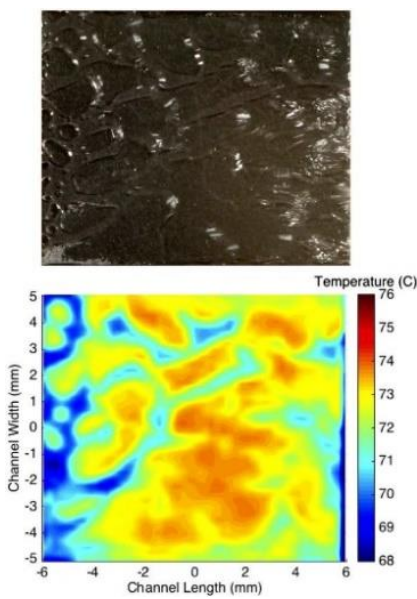

(a)


(b)
Fig. 9: Instantaneous photographic and infrared visualization of twophase diabatic microgap flow for FC-72, $q "=7.9 \mathrm{~W} / \mathrm{cm}^{2}, \mathrm{x}_{\text {exit }}=27 \%, \mathrm{~h}_{\text {avg }}$ $=4500 \mathrm{~W} / \mathrm{m}^{2} \mathrm{~K}, \mathrm{G}=210 \mathrm{~kg} / \mathrm{m}^{2}-\mathrm{s}, \Delta \mathrm{T}_{\text {sub }}=5 \mathrm{~K}$, and a $10 \mathrm{~mm}$ by $12 \mathrm{~mm}$ by $0.2 \mathrm{~mm}$ channel (a) Typical and (b) Occasional. Flow is left to right.

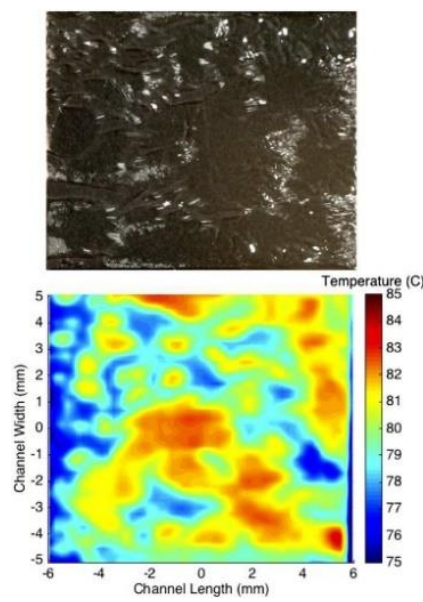

(a)

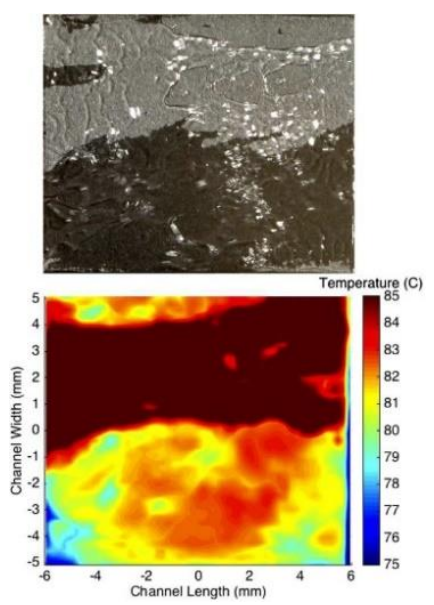

(b)
Fig. 10: Instantaneous photographic and infrared visualization of twophase diabatic microgap flow for FC-72, $q "=15.7 \mathrm{~W} / \mathrm{cm}^{2}, x_{\text {exit }}=45 \%$, $h_{\text {avg }}=5000 \mathrm{~W} / \mathrm{m}^{2} \mathrm{~K}, \mathrm{G}=210 \mathrm{~kg} / \mathrm{m}^{2}-\mathrm{s}, \Delta T_{\text {sub }}=5 \mathrm{~K}$, and a $10 \mathrm{~mm}$ by $12 \mathrm{~mm}$ by $0.2 \mathrm{~mm}$ channel (a) Typical and (b) Occasional. Flow is left to right.

For the highest heat flux of $17.7 \mathrm{~W} / \mathrm{cm}^{2}$ and exit quality of $61 \%$, bubbly and intermittent flow is still observed in the first half of the channel, though at relatively high wall excess temperatures of $40 \mathrm{~K}$. But-despite the pulsatile flow in the channel and the relatively high liquid fraction available (approximately 40\%) - the flow appears not to wet the second half of the channel, leading to a broad area of elevated wall temperature, reaching a superheat of more than $45 \mathrm{~K}$. While thin film annular flow could have been expected under these flow conditions (based on flow regime predictions), the observed elevated temperatures and the visual imagery in Fig. 11(a) are indicative of wall dryout in the second half of the channel, which grows, periodically, to cover the majority of the channel, as shown in Fig. 11(b). Interestingly, under these conditions, 3D waves, rivulets, and hole formations are observed in the sheardriven film on the upper channel surface (the sapphire window), which is only weakly heated by conduction from the heated copper test section into the upper sapphire window.


(a)

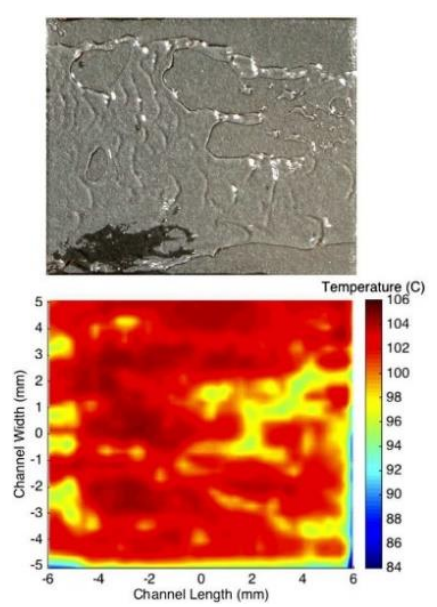

(b)
Fig. 11: Instantaneous photographic and infrared visualization of twophase diabatic microgap flow for FC-72, q" $=17.7 \mathrm{~W} / \mathrm{cm}^{2}, \mathrm{x}_{\mathrm{exi}}=61 \%$, $h_{\text {avg }}=4800 \mathrm{~W} / \mathrm{m}^{2} \mathrm{~K}, \mathrm{G}=210 \mathrm{~kg} / \mathrm{m}^{2}-\mathrm{s}, \Delta T_{\text {sub }}=5 \mathrm{~K}$, and a $10 \mathrm{~mm}$ by $12 \mathrm{~mm}$ by $0.2 \mathrm{~mm}$ channel (a) Typical and (b) Occasional. Flow is left to right.

The stability and integrity of the liquid-vapor interface in two-phase flow results from the interplay between stabilizing (gravity, surface tension, and viscous damping) and destabilizing (inertia, mass loss, evaporative recoil, and thermocapillary) forces. From analyzing the visualization shown in Fig. 8 to Fig. 11, it would appear that the lower liquid film is periodically rupturing and dewetting the heated surface, resulting in a subsequent rise in the local wall temperature. It is, however, unclear which destabilizing mechanisms are primarily responsible for this periodic occurrence of film rupture and elevated wall temperatures. Findings from Kabov, Lyulin, Marchuk, and Zaitsev [38] and Gatapova and Kabov [39] have shown that nonuniformities in surface temperature can lead to significant thermocapillary forces that in turn induce spatial variations in the film's thickness. Regions of localized thinning (negative temperature gradients) are thus especially susceptible to film rupture. For elevated heat fluxes and qualities, it also appears that, in a manifestation of a Leidenfrost-like behavior, the available liquid in the flow is unable to migrate against the flow of generated vapor and rewet the heated surface.

The average heat transfer coefficients for the conditions examined in this study are plotted in Fig. 12, above the flow regime maps, as a function of average superficial vapor velocity, along with the Chen [40] and Shah [41,42] correlations. The spatially and temporally averaged microgap heat transfer coefficient varied only slightly from $4300 \mathrm{~W} / \mathrm{m}^{2}-\mathrm{K}$ at an exit quality of $9 \%$, to a peak of $5000 \mathrm{~W} / \mathrm{m}^{2}-\mathrm{K}$ at an exit quality of $45 \%$, and to a slightly lower value of $4800 \mathrm{~W} / \mathrm{m}^{2}-\mathrm{K}$ at the highest exit quality of $61 \%$. While long microgap channels display an M-shaped variation in the heat transfer coefficient and both the Chen and Shah correlations predict that the heat transfer coefficient will rise with increasing quality over the 
range studied, the experimental data fails to reveal such trends and, in light of the experimental uncertainty experienced in this study, must be considered invariant across the experimental range.
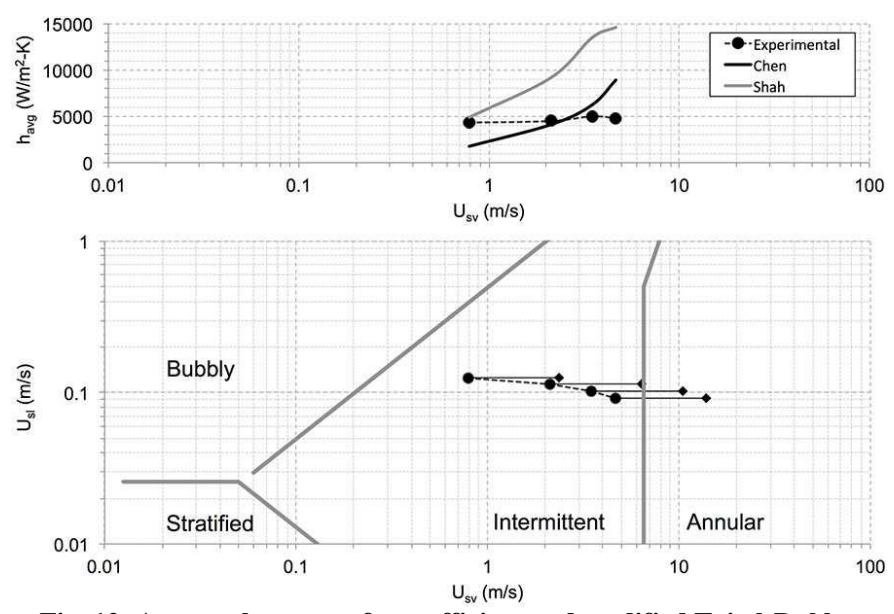

Fig. 12: Average heat transfer coefficient and modified Taitel-Dukler flow regime map for two-phase diabatic micro- gap flow with FC-72, G = $210 \mathrm{~kg} / \mathrm{m}^{2}-\mathrm{s}, \Delta \mathrm{T}_{\text {sub }}=5 \mathrm{~K}$, and a $10 \mathrm{~mm}$ by $12 \mathrm{~mm}$ by $0.2 \mathrm{~mm}$ channel.

Interestingly, the single-phase liquid and vapor heat transfer coefficient values for this microgap channel at the stated mass flux are approximately 530 and $660 \mathrm{~W} / \mathrm{m}^{2}-\mathrm{K}$, respectively, indicating that there is, nevertheless, a nearly order-ofmagnitude two-phase enhancement relative to all-liquid or allvapor flow for the conditions of this microgap channel. Moreover, this "two-phase multiplier" of the average heat transfer coefficient is in close agreement with the data from BarCohen, Rahim, and Ali [27] and Rahim and Bar-Cohen [36], under similar conditions - a $10 \mathrm{~mm}$ by $14 \mathrm{~mm}$ by $0.2 \mathrm{~mm}$ microgap channel, using a thermally simulated silicon test chip with FC-87 as the working fluid at a mass flux of $300 \mathrm{~kg} / \mathrm{m}^{2}-\mathrm{s}$ (Fig. 13). It, thus, appears that the dominance of churn flow in the chip-scale microgap channel, with periodic flow of confined bubbles and slugs, rather than the orderly progression from bubble to intermittent to annular flow and the observed periodic channel dryout, becoming ever more frequent with increasing heat flux and quality, can explain the failure to observe the Mshaped heat transfer coefficient variation. It should be noted that this present work and the prior chip-scale study are limited to relatively small mass fluxes of 210 to $300 \mathrm{~kg} / \mathrm{m}^{2}$-s, and it may very well be that this observed thermal behavior and quality invariance is unique to low mass flux flow.

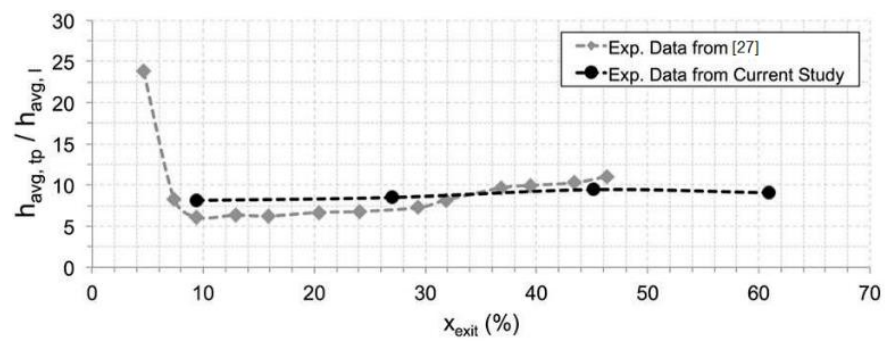

Fig. 13: Average two-phase multiplier (ratio of two-phase to all-liquid heat transfer coefficients) compared with similar data from Rahim, BarCohen, and Ali [27]. Conditions for current study: FC-72, G $=210 \mathrm{~kg} / \mathrm{m}^{2}-$ $\mathrm{s}, \Delta T_{\text {sub }}=5 \mathrm{~K}$, and a $10 \mathrm{~mm}$ by $12 \mathrm{~mm}$ by $0.2 \mathrm{~mm}$ channel. Conditions for [27]: FC-87, $\mathrm{G}=300 \mathrm{~kg} / \mathrm{m}^{2}-\mathrm{s}, \Delta \mathrm{T}_{\text {sub }}=5 \mathrm{~K}$, and a $10 \mathrm{~mm}$ by14 $\mathrm{mm}$ by 0.2 mm channel.

\section{ORIENTATION EFFECTS IN TWO-PHASE MiCROGAP COOLERS}

To satisfy the requirements of an array of embedded cooling applications and to reduce limitations on the "use scenarios" compatible with two-phase cooling systems, an ideal evaporative microcooler would be insensitive to orientation effects. While the flow regimes observed in channels experiencing two-phase flow are determined by a subtle balance among the prevailing gravitational, inertial, and capillary forces, it is generally expected that with diminishing diameters, gravitational forces will weaken and inertial and capillary forces will dominate the two-phase flow behavior [43]. It may, thus, be argued that orientation-insensitive behavior should be encountered in microchannel geometries.

Unfortunately, despite close to 40 years of microchannel research, dating back to the seminal work of Tuckerman and Pease [44], as well as the studies summarized in more recent textbooks $[45,46]$, there is no single, widely-agreed criteria for the diameter below which orientation- and gravity-insensitive "microchannel" behavior can be guaranteed. Early criteria defined the transition to microscale behavior based on manufacturing techniques $[47,48]$. Subsequent efforts attempted to capture the changes in the two-phase thermofluid behavior, including bubble distortion and pressure drop [49], absence of stratification [50,51], bubble and slug confinement [52,53], flow pattern transitions [54-57], and film thickness uniformity in intermittent and annular flows [51,58,59]. While efforts have been made to establish microscale criteria based on channel geometry alone, much of the relevant literature deals with various ratios between gravitational forces and surface tension forces in the channel, which can be re-arranged into the Bond number, defined as

$$
B o=\frac{\left(\rho_{l}-\rho_{v}\right) \cdot g \cdot D^{2}}{\sigma}
$$

where $\rho_{l}$ is the density of the liquid phase, $\rho_{v}$ is the density of the vapor phase, $g$ is the acceleration due to gravity, $D$ is the channel diameter, and $\sigma$ is the surface tension of the working fluid. In addition to the Bond number (or some variation of it), some definitions have included the Weber, Froude, or Reynolds numbers as parameters in defining the transition to microscale two-phase behavior. The Weber number is defined as

$$
W e=\frac{G^{2} \cdot D}{\rho_{m} \cdot \sigma}
$$

where $G$ is the mass flux and $\rho_{m}$ is the mean density of the liquid and vapor. The Froude number is defined below.

$$
F r=\sqrt{\frac{W e}{B o}}=\frac{G}{\sqrt{\rho_{m} \cdot\left(\rho_{l}-\rho_{v}\right) \cdot g \cdot D}}
$$

The Reynolds number is defined as

$$
R e=\frac{G \cdot D}{\mu_{l}}
$$

where $\mu_{l}$ is the liquid viscosity. 
Reynolds, Saad, and Satterlee [60] developed a dominant force regime map that included regions dominated by surface tension, gravity, and inertia. They proposed that surface tension dominated when $B o<1$ and $W e<1$, gravity dominated when $B o>1$ and $F r<1$, and inertia dominated when $B o>1$ and $\mathrm{Fr}>1$. Baba et al. [61] found slightly different boundaries, with surface tension dominating when $B o<0.31$ and $W e<5$, gravity dominating when $\mathrm{Bo}>0.31$ and $\mathrm{Fr}<4$, and inertia dominating when $B o>0.31$ and $F r>4$. Harirchian and Garimella [53] found that flows become confined-and therefore behaved as microchannels-when $B o^{0.5} \cdot R e<160$.

The inclusion of factors beyond the Bond number in some criteria prevents a comparison of all of the proposed microscale criteria using the Bond number alone. Accordingly, Fig. 14 shows the threshold microscale diameter for circular channels proposed in the various works discussed in this section of the paper. The data sets are sorted by the threshold diameter for water and it was assumed that the velocity was sufficiently low for the flow not to be inertia dominated for criteria that consider inertial effects. The most conservative estimates for the transition to microscale two-phase behavior in circular channels are $0.336,0.237$, and $0.191 \mathrm{~mm}$ for water, R245fa, and HFE7100, respectively, and the most relaxed values are 15.7, 6.65 , and $5.36 \mathrm{~mm}$, respectively, a range of nearly $15 \mathrm{x}$ between the most conservative and most relaxed criteria. The horizontal black line in the figure is at $0.43 \mathrm{~mm}$, representing the hydraulic diameter of the $0.22 \mathrm{~mm}$ by $13.0 \mathrm{~mm}$ microgap channel discussed later in this section.

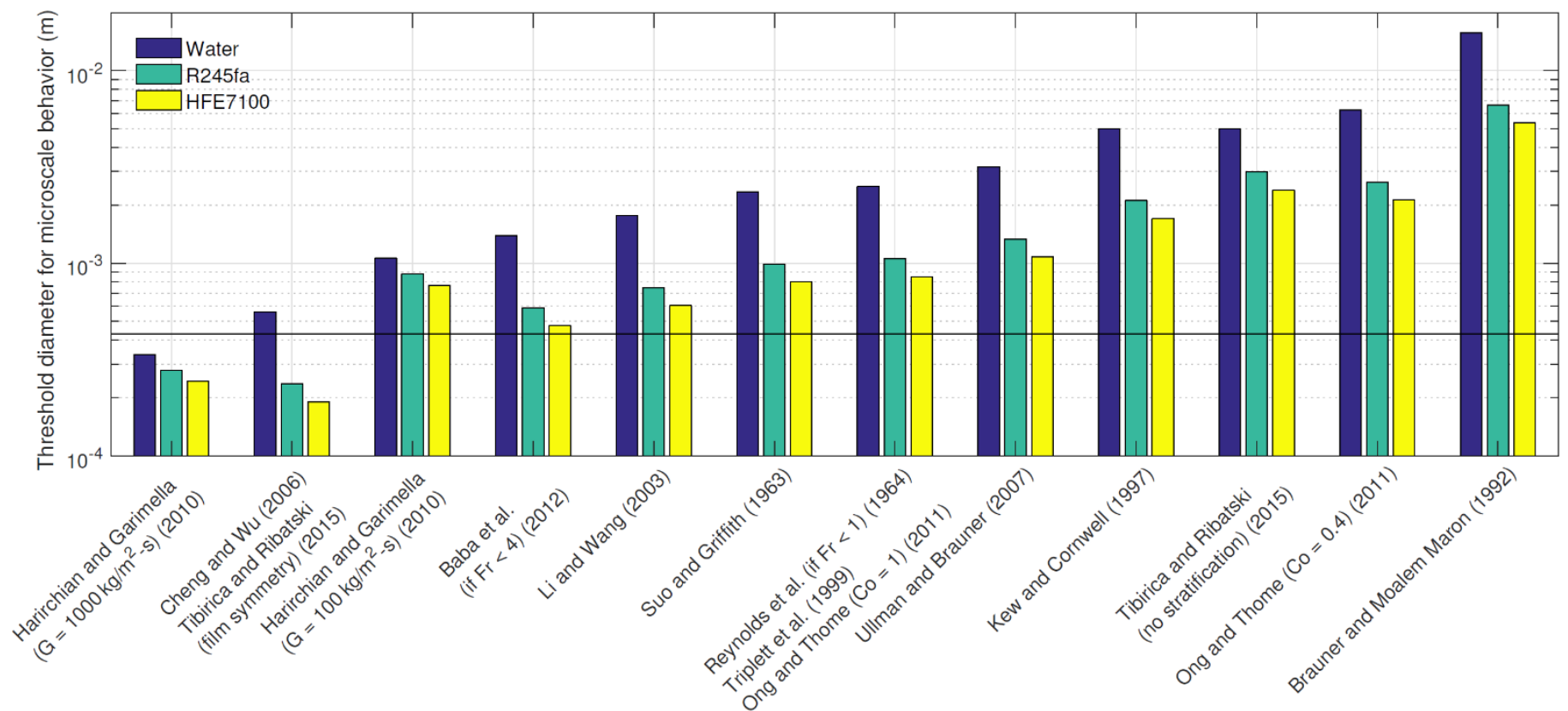

Fig. 14: Threshold microscale diameters for circular channels proposed by various authors for water, R245fa, and HFE7100 at $101.3 \mathrm{kPa}$ (horizontal black line at $0.43 \mathrm{~mm}$ represents hydraulic diameter of $0.22 \mathrm{~mm}$ high by 13.0 mm wide channel used in present work)

Beyond the broad range of microscale channel dimensions that results from the various criteria, much of the research into orientation effects on two-phase flows has focused on circular tubes or rectangular tubes with aspect ratios near unity, making it difficult to extrapolate such results to microgap channels. Furthermore, Ullman and Brauner [56] and Baldassari and Marengo [62] suggested that the appropriate formulation of the Bond number for rectangular ducts should scale the surface tension term with the channel width and scale the gravity term with the channel dimension parallel to the gravity vector. With this formulation, the length scale in the gravity term could be the channel height, width, or length, depending on the evaporator orientation. Regarding the scaling of the surface tension with the channel width, it is unresolved whether this formulation is appropriate for microgap coolers, in which the liquid-vapor interface rarely spans the entire channel width.

As a first step toward understanding the effect of evaporator orientation on two-phase microgap flow and transport, an experimental apparatus was designed and assembled to provide two-phase flow test data with the evaporator in various orientations with respect to the gravity vector. The flow loop supplied degassed and slightly subcooled $\left(\Delta T_{\text {sub }}=2-6 K\right)$ HFE7100 to the evaporator test section at the prescribed flow rate, temperature, and pressure. The microgap cooler dimensions were $13.0 \mathrm{~mm}$ wide by $0.22 \mathrm{~mm}$ high by $12.7 \mathrm{~mm}$ long, yielding a hydraulic diameter of $0.43 \mathrm{~mm}$, approximately twice as large as suggested for HFE7100 by the most conservative criterion for orientation insensitivity, but about 13 times smaller than the most relaxed microscale criterion.

A $12.7 \mathrm{~mm}$ by $12.7 \mathrm{~mm}$ thermal test chip with embedded temperature sensors served as the uniform heat source. The evaporator was tested in five configurations: horizontal - heater up, vertical upflow, horizontal - heater down, vertical downflow, and sideways (i.e., with the channel width parallel to the gravity vector). The corresponding range of Bond numbers, calculated using the channel width for the surface tension term and the dimension parallel to the gravity vector for the gravity term was 3.9 to 233 . The Bond number based on the hydraulic diameter 
alone was 0.25 . For a mass flux range of 350 to $850 \mathrm{~kg} / \mathrm{m}^{2}$-s, the corresponding Weber and Froude numbers (calculated using the channel hydraulic diameter) are 4.0 to 21.3 and 3.9 to 9.1 , respectively, which suggests that the flows will be dominated by inertia (Reynolds, Saad, and Satterlee [60] boundaries) or surface tension at the lowest mass flux and inertia at the higher mass fluxes (Baba et al. [61] boundaries).

Fig. 15 shows the single- and two-phase heat transfer coefficients (HTCs) achieved near the channel outlet for each of the five evaporator orientations and for mass fluxes ranging from 350 to $380 \mathrm{~kg} / \mathrm{m}^{2}$-s. As expected, the single-phase HTCs, at approximately $1.5 \mathrm{~kW} / \mathrm{m}^{2}-\mathrm{K}$, are much lower than the twophase HTCs, which range up to $8 \mathrm{~kW} / \mathrm{m}^{2}-\mathrm{K}$. Most significantly, despite some variation in the onset of nucleate boiling, the heat transfer coefficients agree well across the five orientations, as evidenced by the near overlap of the five curves over much of the heat flux range. Similar behavior-in terms of the heat transfer coefficient enhancement after the onset of nucleate boiling and minimal variation of the heat transfer coefficient as a function of evaporator orientation-was observed for mass fluxes of 600 and $830 \mathrm{~kg} / \mathrm{m}^{2}$-s. Additional details on those results are provided in [22].

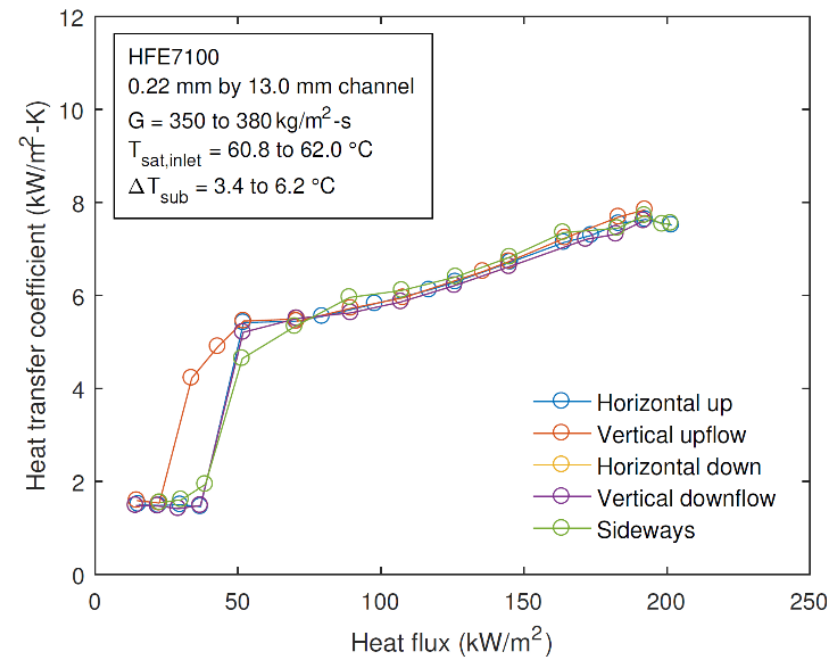

Fig. 15: Single- and two-phase heater transfer coefficients near the channel outlet as a function of heat flux and evaporator orientation

[22]

Fig. 16 shows the critical heat flux (CHF) achieved at three mass flux increments with the evaporator in five orientations. $\mathrm{CHF}$ increased with increasing mass flux for all orientations, as expected. The $\mathrm{CHF}$ achieved at each mass flux among the five orientations agreed within the experimental uncertainty and variation in the mass flux. Across the five orientations, the maximum to minimum variation in mass flux was $6.2 \%$ of the average at the lowest mass flux, $3.2 \%$ of the average at the intermediate mass flux, and $3.6 \%$ of the average at the highest mass flux. The mass flux will be controlled more carefully in future experiments to reduce this potential contribution to the small variation in $\mathrm{CHF}$ observed across orientations.

Collectively, the two-phase results revealed that evaporator orientation played a negligible role in the heat transfer coefficients and CHF achieved within the specified microgap cooler, thus confirming the expectation that a microchannel diameter - sized to fall close to the most conservative definition of a microchannel-will yield orientation-insensitive two-phase behavior. These results call into question the applicability of the formulation of the Bond number for rectangular ducts that scales the surface tension term with the channel width and scales the gravity term with the channel dimension parallel to the gravity vector for assessing the transition to orientation-independent, microscale behavior since such formulations produce Bond numbers roughly six times larger than any of the microscale Bond numbers reported in the literature. Additional work is required to assess the efficacy of the Bond number for predicting the microscale transition for microgap coolers and/or to determine the appropriate length scales for calculating the Bond number (and other non-dimensional parameters) for noncircular channels, especially those with high aspect ratio.

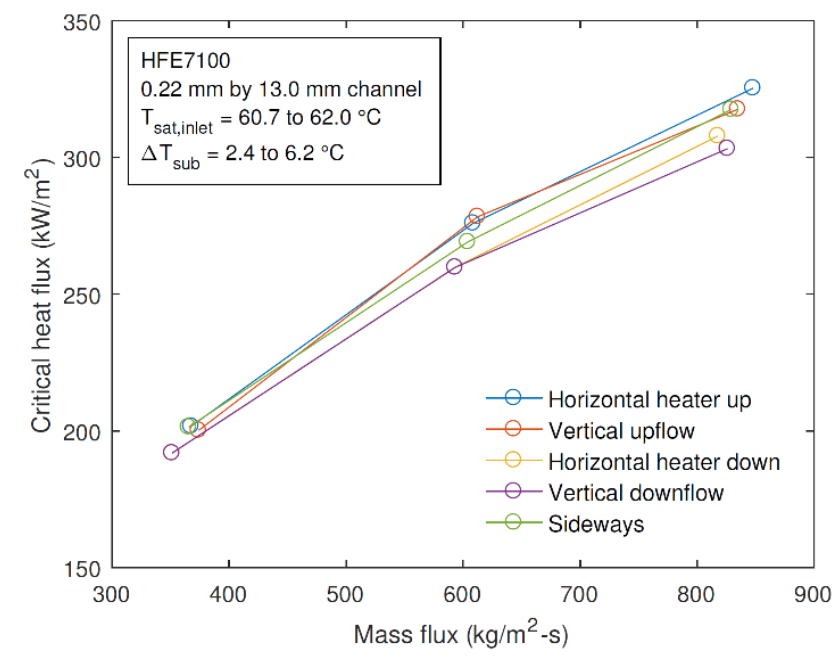

Fig. 16: Flow boiling CHF as a function of mass flux and evaporator orientation [22]

Future work, using the existing test facility, will include microgap heights from 0.1 to $1.0 \mathrm{~mm}$ and mass fluxes from 100 to $1000 \mathrm{~kg} / \mathrm{m}^{2}$-s to produce experimental results covering a broad range of Bond, Weber, and Froude numbers. These results will clarify the relative contributions of gravity, surface tension, and inertia on two-phase flow behavior, ultimately facilitating the development of more accurate microscale definitions and dominant force maps for microgap channels.

\section{CEnTRIPETAl ACCELERATION IN MANifOld-FED U- SHAPED MICROGAP CHANNELS}

Manifolded microchannel (MMC) geometries, of the type shown in Fig. 17, have demonstrated the ability to remove high heat fluxes while maintaining modest pressure drops (less than 100 to $200 \mathrm{kPa}$ at the highest heat fluxes) in embedded cooling applications [63]. MMC geometries are a matrix of parallel microgap channels, fed by larger out-of-plane liquid channels interspersed with even larger vapor channels acting as chimneys for escaping vapor. For embedded cooling, microgrooves are etched in the inactive side of the chip. A manifold with alternating inlets and outlets is then stacked on the microgrooved chip, splitting the flow length in the grooves into much shorter lengths to reduce the pressure drop. For high heat transfer coefficients, the microgrooves are high aspect ratio, having a hydraulic diameter much smaller than the width of the channels. 
The width of channels is the same as the depth of the grooves etched into the chip, and because the inlet and outlet of the microgap channels exist on the side of the microgap, the flow follows a U-shaped flow path through the gap.

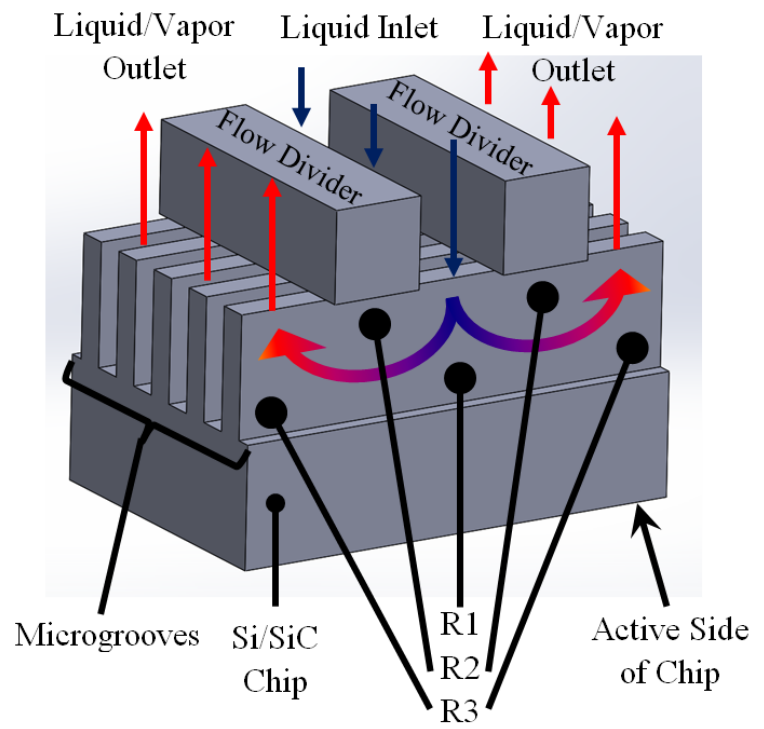

Fig. 17: Illustration of MMC geometry. Manifolded microgrooves create a matrix of $U$-shaped microgap channels in the inactive side of a chip. Regions of interest in individual $U$-shaped microgap flows are identified: R1 - divergence zone, R2 - interior of bend, R3 - exterior corner

While many studies in the literature - as discussed in Section IV-distinguish microchannel behavior from minichannel and macrochannel behavior by the dominance of inertial and capillary forces over gravitational forces, the small radius of curvature of flow paths in MMC configurations are not bound by these relationships. Depending on mass flux and vapor quality, the centripetal acceleration can range from 5 to $10^{7}$ times that of gravitational buoyancy in straight horizontal channels. The spanwise pressure gradient due to buoyancy is

$$
\Delta P=\left(\rho_{l}-\rho_{v}\right) \cdot D_{h} \cdot \frac{v^{2}}{R}
$$

where $\rho_{l}$ is the liquid density, $\rho_{v}$ is the vapor density, $D_{h}$ is the channel hydraulic diameter, $v$ is the flow velocity, and $R$ is the radius of curvature of the flow path. At low quality, the velocity is near that of single-phase liquid and the resulting centripetal buoyancy is within an order of magnitude of gravitational buoyancy. The centripetal acceleration becomes much larger as quality increases. At qualities approaching unity, the velocity approaches that of single-phase vapor, which can be 10 to 1000 times greater than that of single-phase liquid. While the density of the vapor is 10 to 1000 times less than that of the liquid, it can be seen that the quadratic effect of velocity generates buoyancy forces several orders of magnitude larger than gravitational buoyancy.

Flow path curvature in manifold-fed microgap channels is thus capable of producing enormous body forces that can strongly compete with shear and capillary forces and add significant complexity to transport phenomena in microgap channels. Centripetal acceleration generated by flow curvature causes bubbles to agglomerate at the interior of the bend [64]. Curved channels can also produce an increased wetted perimeter with wavy stratified flows entering the bend [65]. Furthermore, for slug flow entering the U-bend, development of annular flow within the bend can occur [65]. Annular flows may have a thicker film on the exterior wall or interior wall of the bend, depending on quality and the rate of liquid entrainment and deposition [66]. The same phenomena affecting annular film morphology also affect dryout behavior, in which the strong centripetal buoyancy generated by high velocity vapor drives the liquid film to dryout at the exterior of the bend $[65,66]$.

It is well established that high centripetal accelerations alter phase agglomeration in the spanwise direction, and therefore alter dryout occurrence relative to the behavior found in straight channels. However, it is difficult to conclude from the literature whether high centripetal accelerations shift the flow regime transitions. If gravitational acceleration is replaced with centripetal acceleration in the robust flow regime correlation developed by Ong and Thome [57], it can be seen by inspection that the flow regime transition boundaries of bubble-to-slug and slug-to-annular are expected to shift to lower qualities with increasing acceleration. Contrarily, in the flow regime maps proposed by Taitel [67] the bubble-to-slug transition is dependent on void faction alone, and therefore is expected to be independent of acceleration. In the same work of Taitel [67], the slug-to-annular transition may also be dependent on void fraction and therefore independent of gravitational or centripetal acceleration as well. At higher mass fluxes, though, the bubbleto-slug transition boundary may be positively proportional to gravity or centripetal acceleration, shifting the boundary to higher quality values. Therefore, the flow regime transition dependence on centripetal acceleration is a topic worthy of additional research.

A recent heat transfer study with embedded MMC's in a silicon carbide ( $\mathrm{SiC}$ ) test chip removed $1 \mathrm{~kW}$ of heat from a $1 \mathrm{~cm}^{2}$ chip with R245fa flowing at $1400 \mathrm{~kg} / \mathrm{m}^{2}-\mathrm{s}$, with an estimated inlet pressure of $400 \mathrm{kPa}$ [63]. The flow was split into 10 inlets and 11 outlets for 500 microgrooves, forming 10,000 U-shaped microgap flow paths. With a temperature rise above the R245fa saturation temperature (in the vicinity of $30^{\circ} \mathrm{C}$, increasing with mass flux and outlet quality) of less than $100^{\circ} \mathrm{C}$, the heat transfer coefficient - across the base area of the chipexceeded $100 \mathrm{~kW} / \mathrm{m}^{2}-\mathrm{K}$. Moreover, as seen in Fig. 18, the heat transfer coefficient variation with increasing quality was different from that exhibited in large L/D axial flow microgap channels and somewhat more similar to the observed behavior in chip-scale channels. For flow rates of $3 \mathrm{~g} / \mathrm{s}$ and $6 \mathrm{~g} / \mathrm{s}$, or mass fluxes of $700 \mathrm{~kg} / \mathrm{m}^{2}$-s and $1400 \mathrm{~kg} / \mathrm{m}^{2}$-s, respectively, of R245fa it can be seen that at low quality, the heat transfer coefficients rise dramatically to a peak near $30 \%$ quality, after which there is a rapid decline toward a gently sloping asymptote with the heat transfer coefficients remaining approximately constant, for a given mass flux, as the outlet quality approaches $100 \%$. Interestingly, while there is less than a $10 \%$ difference in peak heat transfer coefficients between the two mass fluxes, the high flow rate conditions yielded a heat transfer coefficient asymptote almost twice as high as the low flow rate condition, with values approaching $30 \mathrm{~kW} / \mathrm{m}^{2}-\mathrm{K}$ at $1400 \mathrm{~kg} / \mathrm{m}^{2}-\mathrm{s}$ and only $17 \mathrm{~kW} / \mathrm{m}^{2}-\mathrm{K}$ at $700 \mathrm{~kg} / \mathrm{m}^{2}-\mathrm{s}$. 


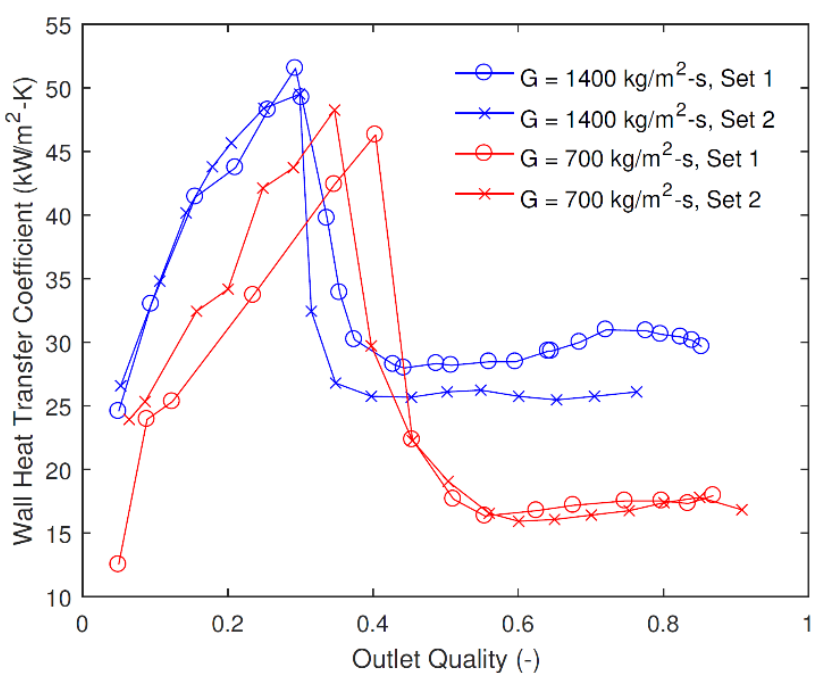

Fig. 18: Channel wall heat transfer coefficient with quality for an embedded MMC chip cooler operating with R245fa with inlet pressures ranging from approximately $10 \mathrm{kPa}$ to $400 \mathrm{kPa}[63]$

A preliminary visualization study on the two-phase flow phenomena occurring in U-shaped microgap channels offers some insight into the mechanisms at work in such channels [24]. The study showed that the phenomena in U-shaped microgap channels exhibit similarities with straight microgap channels with additional unique phenomena. The sharp corners in the fluid flow path caused stagnant zones of low mass flux. The regions of interest are specified in Fig. 17 as R1, R2, and R3, and were labeled the "interior of bend, divergence zone, and exterior corner region," respectively. Each of these zones in the channel generated large slugs under a variety of conditions, even with bubble flow or annular flow occurring adjacent to slug generation in the channel. At low quality, the bubbles traveled to the interior of the bend due to centripetal acceleration buoyancy - a trend similar to that of macroscale, circular Ubend channels - which further exacerbated the growth and low velocity of slugs agglomerated at the interior of the bend. The slugs generated in the stagnant regions often flowed to the outlet independent of the prevailing flow regime in the channel, meaning that slug flow occurred over a wider range of conditions than would be expected in straight channels occurring simultaneously with the prevailing flow regime. At higher qualities, slug formation was no longer observed and annular flow was the prevailing flow regime. The observed outlet flow regimes were therefore labeled bubble/slug, slug, slug/annular, and annular. The flow regimes and dryout occurrence were mapped in terms of outlet quality and mass flux for all conditions tested.

It was found that the slug formation in stagnation zones led to liquid film depletion around the slugs, meaning that evaporation temporarily ceased in that area. Because of the stagnation zones in the manifolded-microchannel, local dryout occurred at much lower qualities than would be expected in comparable straight channels. Dryout occurred at all three areas of interest in the channel, but under different conditions in all three regions. Dryout occurred at the lowest qualities at the interior of the bend for all mass fluxes, but became suppressed as quality increased. Dryout in the other two regions - which exist at the outer side of the bend - began to occur at higher quality, but was suppressed with increasing quality. Interestingly, dryout was suppressed in all three regions as the annular flow regime began to dominate. The suppression of dryout in the annular regime was likely due to high vapor shear on the liquid film. Dryout in all three regions was conveniently characterized by superficial vapor velocity at the outlet.

The relationship between these local flow phenomena and global heat transfer coefficients is not fully established. The preliminary results indicate that the peak heat transfer coefficients, like those shown in Fig. 18, occur when the prevailing flow regime is annular and dryout has become suppressed in the three regions of interest. The reduction in heat transfer coefficient after the peak is likely due to the onset of local dryout as quality increases in the annular regime, and is the subject of further investigation.

\section{CONCLUSIONS}

Recent DARPA-funded and corporate research efforts in Embedded Cooling have nearly completed the "inward migration" of thermal management technology, shifting heat extraction from the Gen1 HVAC and Gen2 remote cooling techniques into the chip and substrate where heat is being generated. The dramatic demonstrated $\mathrm{kW}$-level singletransistor cooling rates provide a most compelling validation of Embedded Cooling and set the stage for commercial and military applications of this Gen3 thermal management paradigm. However, if such efficient $\mathrm{kW}$-level heat removal is to be extended from single transistors to transistor arrays, larger chips, and chip stacks, it will be necessary to fully exploit embedded evaporative cooling, based on a fundamental understanding of the underlying hydrodynamic behavior and thermal characteristics of two-phase flow in manifold-supplied chip-scale coolers operating in a variety of orientations.

In studies performed in the Thermal Management of Photonic and Electronic Systems Laboratory at the University of Maryland:

- "Churn flow" has been found to dominate high-quality, two-phase cooling in chip-scale microgap channels, with periodic flow of confined bubbles and slugs, rather than the orderly progression across the established flow regimes, leading to a low-quality peak followed by a steep decrease to an axially-invariant heat transfer coefficient;

- Evaporator orientation has been found to play a negligible role in two-phase heat transfer coefficients and critical heat flux of a microgap cooler sized to fall close to the most conservative microscale definition, although additional work is required to determine the appropriate length scales for computing the non-dimensional numbers associated with such microscale criteria; and

- Manifolded microchannel geometries have been found to be effective in removing heat fluxes as high as $1 \mathrm{~kW} / \mathrm{cm}^{2}$ and the very high centripetal accelerations in such coolers have been found to play a dominant role in the resultant two-phase flow and transport. 


\section{REFERENCES}

[1] A. Bar-Cohen, "Towards Embedded Cooling - Gen-3 Thermal Packaging Technology," Chapter 16 in "Cooling of Microelectronic and Nanoelectronic Equipment: Advances and Emerging Research," M. Iyengar, K. J. L. Geisler, and B. Sammakia (eds), World Scientific Publishing Company: Singapore, 2014.

[2] A. Bar-Cohen, "Gen-3 thermal management technology: role of microchannels and nanostructures in an embedded cooling paradigm," J. Nanotechnol. Eng. Med., 4(2), pp. 020907-1-030907-3, Jul. 2013.

[3] Near Junction Thermal Transport (NJTT), DARPA Broad Agency Announcement DARPA-BAA-11-09, posted Nov. 2010.

[4] Intrachip/Interchip Enhanced Cooling Fundamentals (ICECool Fundamentals), DARPA Broad Agency Announcement DARPA-BAA12-50, posted Jun. 2012.

[5] Intrachip/Interchip Enhanced Cooling Applications (ICECool Applications), DARPA Broad Agency Announcement DARPA-BAA-1321, posted Feb. 2013.

[6] A. Bar-Cohen, "Thermal packaging - from problem solver to performance multiplier," Electronics Cooling Magazine, 4(19), pp. 8-11, Dec. 2013.

[7] A. Bar-Cohen, J. J. Maurer, and A. Sivananthan, "Near-junction microfluidic cooling for wide bandgap devices," Materials Research Society Advances, 1(2), pp. 181-195, 2016.

[8] A. Bar-Cohen, J. J. Maurer, and A. Sivananthan, "Near-junction microfluidic thermal management of RF power amplifiers," IEEE Int. Conf. Microwaves, Communications, Antennas, and Electronic Systems (COMCAS), Nov. 2-4, 2015, Tel Aviv, Israel.

[9] P. - C. Chao, K. Chu, C. Creamer, J. Diaz, T. Yurovchak, M. Shur, R. Kallaher, C. McGray, G. D. Via, and J. D. Blevins, "Low-temperature bonded $\mathrm{GaN}$-on-diamond HEMTs with $11 \mathrm{~W} / \mathrm{mm}$ output power at 10 GHz," IEEE Trans. Electron Devices, 62(11), pp. 3658-3664, Nov. 2015.

[10] M. Tyhach, D. Altman, S. Bernstein, R. Korenstein, J. Cho, K. E. Goodson, D. Francis, F. Faili, F. Ejeckam, S. Kim, and S. Graham, "S2T3: Next generation hallium nitrude HEMTs enabled by diamond substrates," Lester Eastman Conf. High Performance Devices (LEC), Aug. 5-7, 2014, Ithaca, NY, USA.

[11] J. Pomeroy, M. Bernardoni, A. Sarua, A. Manoi, D. C. Dumka, D. M. Fanning, M. Kuball, "Achieving the best thermal performance for GaNon-diamond," IEEE Compound Semiconductor Integrated Circuit Symposium (CSICS), Oct. 13-16, 2013, Monterey, CA, USA.

[12] E. Bozorg-Grayeli, A. Sood, M. Asheghi, V. Gambin, R. Sandhu, T. I. Feygelson, B. B. Pate, K. Hobart, and K. E. Goodson, "Thermal conduction inhomogeneity of nanocrystalline diamond films by dual-side thermoreflectance," Appl. Phys. Lett., 102, pp 11907-1-11907-4, 2013.

[13] J. E. Graebner, S. Jin, G. W. Kammlott, J. A. Herb, C. F. Gardinier, "Large anisotropic thermal conductivity in synthetic diamond films," Nature, 359, pp. 401-403, Oct. 1992.

[14] D. H. Altman, A. Gupta, and M. Tyhach, "Development of a diamond microfluidics-based intra-chip cooling technology for GaN," ASME Int. Technical Conf. and Exhibition on Packaging and Integration of Electronic and Photonic Microsystems (InterPACK), Jul. 6-9, 2015, San Francisco, CA, USA.

[15] A. Bar-Cohen, J. J. Maurer, and D. H. Altman, "Gen3 Embedded Cooling for High Power RF Components," Plenary Lecture, IEEE Int. Conf. Microwaves, Communications, Antennas, and Electronic Systems (COMCAS), Nov. 13-15, 2017, Tel Aviv, Israel.

[16] T. Brunschwiler, S. Paredes, U. Drechsler, B. Michel, W. Cesar, Y. Levlebici, B. Wunderle, and H. Reichl, "Heat-removal performance scaling of interlayer cooled chip stacks," IEEE Intersociety Conf. on Thermal and Thermomechanical Phenomena in Electronic Systems (ITherm), Jun. 2-5, 2010, Las Vegas, NV, USA.

[17] M. D. Schultz, P. R. Parida, M. Gaynes, O. Ozsun, G. McVicker, U. Drechsler, T. Chainer, "Microfluidic two-phase cooling of a high power microprocessor part A: Design and fabrication," IEEE Intersociety Conf. on Thermal and Thermomechanical Phenomena in Electronic Systems (ITherm), May 30-Jun. 2, 2017, Orlando, FL, USA.

[18] M. D. Schultz, P. R. Parida, M. Gaynes, O. Ozsun, G. McVicker, U. Drechsler, T. Chainer, "Microfluidic two-phase cooling of a high power microprocessor part B: Test and characterization,” IEEE Intersociety Conf. on Thermal and Thermomechanical Phenomena in Electronic Systems (ITherm), May 30-Jun. 2, 2017, Orlando, FL, USA.

[19] M. Bakir, "Die-level embedded cooling \& thermal isolation in 2.5D/3D ICs and electrical benchmarking," Panel Presentation, IEEE Intersociety Conf. on Thermal and Thermomechanical Phenomena in Electronic Systems (ITherm), May 30-Jun. 2, 2017, Orlando, FL, USA.

[20] A. Bar-Cohen, C. Holloway, A. Kaffel, and A. Riaz, "Waves and instabilities in high quality adiabatic flow in microgap channels," Int. J. Multiphase Flow, 83, pp. 62-76, Jul. 2016.

[21] A. Bar-Cohen and C. A. Holloway, "Thermofluid characteristics of highquality flow in chip-scale microgap channels," Interfacial Phenomena and Heat Transfer, 3(4), pp. 393-412, 2015.

[22] F. Robinson and A. Bar-Cohen, "Gravity effects in microgap flow boiling," IEEE Intersociety Conf. on Thermal and Thermomechanical Phenomena in Electronic Systems (ITherm), May 30-Jun. 2, 2017, Orlando, FL, USA.

[23] D. C. Deisenroth, M. Ohadi, and A. Bar-Cohen, "Two-phase flow regimes in a U-shaped diabatic manifolded-microgap channel," IEEE Intersociety Conf. on Thermal and Thermomechanical Phenomena in Electronic Systems (ITherm), May 30-Jun. 2, 2017, Orlando, FL, USA.

[24] D. C. Deisenroth, A. Bar-Cohen, and M. Ohadi, "Geometry effects on twophase flow regimes in a diabatic manifolded microgap channel," ASME International Technical Conf. and Exhibition on Packaging and Integration of Electronic and Photonic Microsystems (InterPACK), Aug. 29Sepetember 1, 2017, San Francisco, CA, USA.

[25] J. R. Thome, A. Bar-Cohen, R. Revellin, and I. Zun, "Unified mechanistic multiscale mapping of two-phase flow patterns in microchannels," Exp. Thermal Fluid Science, 44, pp. 1-22, Jan. 2013.

[26] E. Rahim, R. Revellin, J. Thome, and A. Bar-Cohen, "Characterization and prediction of two-phase flow regimes in miniature tubes," Int. J. Multiphase Flow, 37(1), pp. 12-23, Jan. 2011.

[27] E. Rahim, A. Bar-Cohen, and I. A. Ali, "Two-phase microgap cooling of a thermally-simulated microprocessor chip," IEEE Intersociety Conf. on Thermal and Thermomechanical Phenomena in Electronic Systems (ITherm), May 30-Jun. 1, 2012, San Diego, CA, USA.

[28] D.-W. Kim, E. Rahim, A. Bar-Cohen, and B. Han, "Direct submount cooling of high-power LEDs," IEEE. Trans. Compon. Packaging Tech., 33(4), pp. 698-712, Dec. 2010.

[29] T. Alam, P. S. Lee. C. R. Yap, and L. Jin, "Experimental investigation of local flow bloiling heat transfer and pressure drop characteristics in microgap channel,” Int. J. Multiphase Flow, 42, pp. 164-174, Jun. 2012.

[30] A. Bar-Cohen and E. Rahim, "Modeling and prediction of two-phase microgap channel heat transfer characteristics," Heat Transfer Eng., 30(8), pp. 601-625, 2009.

[31] T.-H. Yen, N. Kasagi, and Y. Suzuki, "Forced convective boiling heat transfer in microtubes at low mass and heat fluxes," Int. J. Multiphase Flow, 29(12), pp. 1771-1792, Dec. 2003.

[32] R. Mastrullo, A. W. Mauro, J. R. Thome, and G. P. Vanoli, " $\mathrm{CO} 2_{2}$ and R410A: Two-phase flow visualization and flow boiling measurements at medium (0.50) reduced pressure," Applied Thermal Eng., 49, pp. 2-8, Dec. 2012.

[33] Y. Yang and Y. Fujita, "Flow boiling heat transfer and flow pattern in rectangular channel of mini-gap," ASME Int. Conf. on Microchannels and Minichannels, Jun. 17-19, 2017, Rochester, NY.

[34] O. A. Kabov, D. V. Zaitsev, V. V. Cheverda, and A. Bar-Cohen, "Evaporation and flow dynamics of thin, shear-driven liquid films in microgap channels," Exp. Thermal Fluid Science, 35(5), pp. 825-831, Jul. 2011

[35] C. A. Holloway, A. Bar-Cohen, and D. Sharar, "Liquid film wave patterns and dryout in microgap channel annular flow," Int. Heat Transfer Conf. (IHTC), Aug. 10-15, 2014, Kyoto, Japan.

[36] Rahim and A. Bar-Cohen, "Thermal characteristics of a chip-scale twophase microgap cooler," Heat Transfer Eng., 36(5), pp. 511-520, 2015.

[37] T. Alam, P. S. Lee, C. R. Yap, L. Jin, and K. Balasubramanian, "Experimental investigation and flow visualization to determine the optimum dimension range of microgap heat sinks," Int. J. Heat Mass Transfer, 55(25-26), pp. 7623-7637, Dec. 2012. 
[38] O. A. Kabov, Y. V. Lyulin, I. V. Mar.uk, and D. V. Zaitsev, "Locally heated shear-driven liquid films in mirochannels and minichannels," Int. J. Heat Fluid Flow, 28(1), pp. 103-112, Feb. 2007.

[39] E. Y. Gatapova and O. A. Kabov, "Shear-driven flows of locally heated liquid films," Int. J. Heat and Mass Transfer, 51(19-20), pp. 4797-4810, Sep. 2008.

[40] J. C. Chen, "Correlation for boiling heat transfer to saturated fluids in convective flow," Ind. Eng. Chem. Process Des. Dev., 5(3), pp. 322-329, Jul. 1966.

[41] M. M. Shah, "A new correlation for heat transfer during boiling flow through pipes," ASHRAE Trans., 82(2), pp. 66-86, Jan. 1976.

[42] M. M. Shah, "Chart correlation for saturated boiling heat transfer: Equations and further study," ASHRAE Trans., 88(1), pp. 185-196, Jan. 1982.

[43] S. G. Kandlikar, "Scale effects on flow boiling heat transfer in microchannels: A fundamental perspective," Int. J. Thermal Sci., 49(7), pp. 1073-1085, Jul. 2010.

[44] D. B. Tuckerman and R. F. W. Pease, "High-performance heat sinking for VLSI,” IEEE Electron Device Letters, 2(5), pp. 126-129, May 1981.

[45] L. P. Yarin, A. Mosyak, and G. Hestroni, Fluid Flow, Heat Transfer and Boiling in Micro-Channels, $1^{\text {st }}$ ed., Berlin: Springer, 2009.

[46] S. Kandlikar, S. Garimella, D. Li, S. Colin, and M. R. King, Heat Transfer and Fluid Flow in Minichannels and Microchannels, $2^{\text {nd }}$ ed., Waltham: Butterworth-Heinemann, 2013.

[47] S. S. Mehendale, A. M. Jacobi, and R. K. Shah, "Fluid flow and heat transfer at micro and meso-scales with application to heat exchanger design," Applied Mechanics Reviews, 53(7), pp. 175-193, Jul. 2000.

[48] S. G. Kandlikar, "Fundamental issues related to flow boiling in minichannels and microchannels," Exp. Thermal Fluid Sci., 36(2-4), pp. 389-407, Jun. 2002.

[49] M. Suo and P. Griffith, "Two-phase flow in capillary tubes," J. Basic Eng., 86(3), pp. 576-582, 1964.

[50] N. Brauner and D. Moalem Maron, "Identification of the range of "small diameters' conduits, regarding two-phase flow pattern transitions," Int. Comm. Heat Mass Transfer, 19, pp. 29-39, 1992.

[51] C. B. Tibirica and G. Ribatski, "Flow boiling phenomenological differences between micro- and macroscale channels," Heat Transfer Eng., 36, pp. 937-942, 2015.

[52] P. A. Kew and K. Cornwell, "Correlations for the prediction of boiling heat transfer in small-diameter channels," Applied Thermal Eng., 17(810), pp. 705-715, 1997.

[53] T. Harirchian and S. Garimella, "A comprehensive flow regime map for microchannel flow boiling with quantitative transition criteria," Int. J. Heat Mass Transfer, 53, pp. 2694-2702, 2010.
[54] K. A. Triplett, S. M. Ghiaasiaan, S. I. Abdel-Khalik, and D. L. Sadowski, "Gas-liquid two-phase flow in microchannels Part I: two-phase flow patterns," Int. J. Multiphase Flow, 25, pp. 377-394, 1999.

[55] K. A. Triplett, S. M. Ghiaasiaan, S. I. Abdel-Khalik, A. LeMouel, and B. N. McCord, "Gas-liquid two-phase flow in microchannels Part II: void fraction and pressure drop," Int. J. Multiphase Flow, 25, pp. 395-410, 1999.

[56] A. Ullmann and N. Brauner, 2007, "The prediction of flow pattern maps in minichannels," Multiphase Sci. Tech., 19(1), pp. 49-73, 2007.

[57] C. L. Ong and J. R. Thome, "Macro-to-microchannel transition in twophase flow: Part 1 - Two-phase flow patterns and film thickness measurements," Exp. Thermal Fluid Sci., 35, pp. 37-47, 2011.

[58] J.-M. Li and B.-X. Wang, "Size effect on two-phase regime for condensation in micro/mini tubes," Heat Transfer - Asian Research, 32(1), pp. 65-71, 2003.

[59] P. Cheng and H. Y. Wu, "Mesoscale and microscale phase-change heat transfer," Advances Heat Transfer, 39, pp. 461-563, 2006.

[60] W. C. Reynolds,M. A. Saad, and H. M. Satterlee, "Capillary hydrostatics and hydrodynamics at low g," Stanford, CA, Stanford University, Dept. of Mechanical Engineering, 1964.

[61] S. Baba, N. Ohtani, O. Kawanami, K. Inoue, and H. Ohta, "Experiments on dominant force regimes in flow boiling using mini-tubes," Frontiers Heat Mass Transfer, 3(4), pp. 1-8, 2012.

[62] C. Baldassari and M. Marengo, "Flow boiling in microchannels in microgravity," Prog. Energy Combustion Sci., 39(1), pp. 1-36, Feb. 2013.

[63] D. G. Bae, R. K. Mandel, S. V. Dessiatoun, S. Rajgopal, S. P. Roberts, M. Mehregany, and M. M. Ohadi, "Embedded two-phase cooling of high heat flux electronics on silicon carbide ( $\mathrm{SiC}$ ) using thin-film evaporation and an enhanced delivery system (FEEDS) manifold-microchannel cooler," IEEE Intersociety Conf. on Thermal and Thermomechanical Phenomena in Electronic Systems (ITherm), May 30-Jun. 2, 2017, Orlando, FL, USA.

[64] K. Usui, S. Aoki, and A. Inoue, "Flow behavior and phase distribution in 2-phase flow around inverted U-bend," J. Nuclear Sci. Tech., 20(11), pp. 915-928, 1983.

[65] R. J. Da Silva Lima and J. R. Thome, "Two-phase flow patterns in Ubends and their contiguous straight tubes for different orientations, tube and bend diameters," Int. J. Refrigeration, 35(5), pp. 1439-1454, Aug. 2012.

[66] G. Berthoud and S. Jayanti, "Characterization of dryout in helical-coils," Int. J. Heat Mass Transfer, 33(7), pp. 1451-1463, Jul. 1990.

[67] Y. Taitel, "Flow pattern transition in two phase flow," Keynote Lecture, Int. Heat Transfer Conf. (IHTC), Jerusalem, Israel, Aug. 19-24, 1990, pp. 237-254. 